\title{
The Assessment of Intellectual Capital in the Egyptian Universities
}

\author{
Dr/ Fayrouz Ramadan Elwakeel ${ }^{1}$, Prof/ Samir Abdelwahab El-Khweet ${ }^{2}$ \\ ${ }^{1}$ Lecturer of Foundations of Education, Faculty of Education, Tanta University \\ ${ }^{2}$ Professor of Foundations of Education, Faculty of Education, Tanta University
}

\begin{abstract}
The purpose of this study is to assess the way Egyptian universities manage its intellectual capital. University is considered as the incubator environment of intellectual capital, as it owns human wealth (human capital) represented in professors with high scientific and practical capabilities, and institutional structures that support innovation and creativity (structural capital), all that lead the university to achieve high rank in the global rankings of universities (relational capital) . But, the Egyptian universities face some challenges, which hinders them to manage its intellectual capital, and accordingly, this lead to the inability of these universities to achieve high ranks in the global university rankings .Accordingly, the current study aimed at recognizing the nature of intellectual capital of 28 Egyptian governmental universities, trying to propose strategic goals to enhance the intellectual capital in order to achieve global excellence. Environmental Analysis Technique (Swot analysis) targeted the whole population of the public universities. Subsequently, the intellectual capital of Egyptian universities has been benchmarked for TIMES performance variables.
\end{abstract}

Keywords: Intellectual capital, Egyptian universities, Human capital, Structural capital, Relational capital, TIMES world university ranking.

\section{Introduction}

Higher Education is considered the ultimate knowledge organizations. The success of any organization depends on the ability to manage its Intellectual capital, considering it as the effective tool for organizations competitiveness. Thus, the most valuable resources in any university are the expertise of its faculty and members, its intellectual capital, therefore the investment in the intellectual capital of universities is a must, as we live in the age of knowledge economy (pourkian, 2014).The term intellectual capital was used for the first time in 1958 AD, when some financial analysts pointed out, in the context of their description of stock market assessments for small companies that are dependent on science work, that their stock valuation work may be called the term intellectual premium. The idea remained asleep after about a quarter of a century, until (Walter Winston), a former president of the American Citicorp Bank, stated that his bank and other organizations possessed intellectual capital of financial value that was not measured by accountants. (Stewart et al, 2009).
Although the use of the term intellectual capital has been launched since $1958 \mathrm{AD}$, it was not embodied as a concept until by the year 1969 AD, where an economist called John Kenneth Galbraith used it as a form of capital that is more than just fixed assets, but it possesses a dynamic element, which gives added value When applied in the business sector, Galbraith thus succeeded in shedding new light on the value of intangible assets in organizations (Jackson, 2002). With the increasing interest in intangible assets, interest in intellectual capital has extended from companies to public institutions such as universities and research centers, as universities are the critical institutional representative and responsible for creativity. Intangible assets are major assets owned by universities and affect the quality of education directly and competitive advantage (Lu, 2012). According to (Siboni,2013) Intellectual capital of the university consists of four main categories, which include:

a) Information Capital, which refers to all information flows, information systems, participatory knowledge and the official knowledge of the university. 
b) Organizational Capital: It refers to a combination of planning, culture, leadership and team work.

c) Relational Capital: It indicates the level of trust the university and its employees enjoy, and the strength of their relationships with stakeholders.

d) Haman Capital: It refers to the total knowledge, skills, and talents that employees of the university possess.

Also,( Tejada\&Ramirez,2016) believes that the intellectual capital of university refers to all intangible assets, and includes: processes and the ability to innovate patents, the tacit knowledge of its members, their capabilities, skills, and talents, as well as the community's recognition of the university, and its network of relationships and alliances. Also, It takes three forms:

a. Human Capital: It refers to the total implicit and explicit knowledge of university employees (professors, researchers, managers, administration, and service workers) that was acquired through formal and informal education and the additional processes involved in its activities.

b. Structural Capital: It refers to the explicit knowledge associated with the internal processes of disseminating, transferring and managing technical and scientific knowledge in the university, and it can be divided into:

i. Organizational Capital: It refers to the environment related to the processes derived from the interaction between research, management, organizational routine, organizational culture, values, internal procedures, quality, and the field of information systems.

ii. Technological Capital: It refers to the technological resources available at the university such as documentary and bibliographic sources, records, technical developments, patents, licenses, software, and databases.

c. Relational Capital: It refers to a wide range of economic and political relations and the institution between the university and non-academic partners, projects, non-profit organizations, local government, and society in general, as it also indicates the perception of others about the university: its image and its attractiveness.

Thus, Intellectual capital includes the talents and abilities of individuals and groups ;technological and social networks and the software and culture that connect them , and intellectual property such as patents , copyrights ,methods ,procedures , archives ,etc. ( Stewart et al ,2009). Some argue that measuring intellectual capital more accurately reflects the true value of an organization and give true insights into core competence, through identifying the interaction between human capital, structural capital, Innovation capital and customer capital (chen et al 2004, Secundo, 2017). With the rapid growth of global competition, there is a need for organizations to control and nature their intellectual capital .while the relationship between intellectual capital and organizational performance have been confirmed, regarding the great importance of the interaction between and among the three forms of intellectual capital of ,human capital, structural capital , and relational Capital ) and global initiatives (ling ,2012).Successful organizations are those which routinely maximize the value from their intellectual capital. Therefore The object of an intellectual capital statement is to give a picture of the corporate effort to build up , develop its resources and abilities in relation to its employees, customers technology and processes (Bontis ,2002)

The regeneration of the intellectual capital highly relies on the universities innovative efforts and learning predisposition where as new knowledge replenishes the advancement of all its intangible resources (Vatamanescue, 2012) .In this respect (Ramirez et al, 2007) urgue that placing the intellectual capital in the framework of universities should be considered apriority, so , researchers should focus on both non-tangible and non-physical resources and assets. According to (Secundo et al, 2015) Entrepreneurial Competence Development is created through processes, each of which has its indicators as follows: Talent attraction and Incubation - Human Resource efficiency and Education for Entrepreneurial Competence Continuing. Therefore, the relationship between intellectual capital and total quality management is embodied in the fact that each of them has a fundamental issue for improving the institution, whether at the strategic or operational level, and both approaches consider measurement as an important component, as better measurement of intellectual capital means that the institution is more able to manage itself and achieve levels Higher than performance and achievement, in addition to that both total quality management and intellectual capital are equally important to achieving the ultimate goal of an improved and more effective institution.(Caddy ,2015) .

\section{Methodology}

An Drawing inspiration from the model approaches proposed by (Cricelli et al ,2018, Secundo et al 2015, Observatory of European University,2006), university is considered as a system with three interacting components ( Human, Structural and Relational ) capital .

Benchmarking is seen as a tool for identifying, understanding and adopting best practices in order to increase operational performance by identifying strategic and operational gaps, in addition to searching for best 
practices that can be applied to bridge these gaps based on criteria of best comparative performance, by adopting the basic criteria for investing in intellectual capital in global elite universities. Thus, benchmarking is used as a tool to understand the current performance levels of the university, and define future goals to achieve a sustainable competitive advantage (Marr, 2004) .Therefore, TIMES (THE) academic ranking of universities in particular, whose importance lies in being based on managing the intellectual capital in the university with its three( human, structural and relational) components, as it relies on analyzing the intangible knowledge assets of the university as indicators of global ranking, and the extent of investing in human capital is inferred from the education index and training, while the structural capital is inferred from the scientific research and citations indicators, in addition to that the relational capital is inferred from the international reputation and return from industry indicators (Adenan et al,2014). Rankings are metric that aims to show the stock and the creation of intellectual capital .Thus, Intellectual capital assessment and evaluation are made by means of the results of TIMES global ranking indicators of universities ,comparative analysis and Benchmarking. Also, Swot Analysis Technique is used to assess the Egyptian universities current position that could help to identify strengths, Weaknesses, opportunities and Threats related to university performance.

The research fundamental objectives are:

- Identify internal and external factors that affect Egyptian universities and to convert weaknesses or threats into strengths or opportunities.

- Determine the extent to which different Egyptian universities have an established language for intellectual capital.

- Propose ways to manage intellectual capital inputs to improve research outputs in universities.

In order to achieve the previously mentioned objectives, (Swot) Analysis Technique is used before deciding on defensive strategy that can help Egyptian universities to manage their intellectual capital effectively. Using (Swot) Analysis Technique is helpful to find competitive advantage by matching the strengths to opportunities, then to connect Weaknesses or Threats to Strengths or opportunities before developing a strategic plane. The information was collected via Content Analysis of governmental reports and statistics. A descriptive Analysis of all texts was conducted according to the characteristics of each of the research questions. Gap Analysis is used to identify gaps between the optimized allocation and integration of the resources, and the current allocation level .This reveals areas in the competence of Egyptian universities that can be improved to achieve the ultimate Aim of the research.

\section{Results}

The experience gained from (swot) analysis provides basis for understanding how Egyptian universities are managing their intellectual capital. As Egyptian universities face a number of challenges that hinders managing its intellectual capital, therefore there are deficiencies in the ability of Egyptian universities to possess competitive advantages.

This was evident in the Arab report for cultural development where it was clarified that the patents registered in the offices of the European Union and the United States of America, Egypt has obtained (three patents) only in the offices of the United States of America, and (nine patents) Only in the offices of the European Union, while in a country like Malaysia - for example - which has a population of approximately 26 million people, it has obtained (181 patents) from the offices of the United States of America, and (35 patents) from the offices of the European Union, Egypt was ranked in terms of patents between 127 countries (No. 82), while the ranking of the State of Kuwait (No.35), while Bahrain and Oman have ranked (No.86) among other countries (The Third Arab Report for cultural development,2010).

In terms of the number of researchers per million people, according to the available numbers documented in a country like Egypt, it turns out that there are (616) Egyptian researchers per million people, while in South Korea there are, for example, about ( 4627) researchers per million people, that is, eight times more than the Egyptian average! (The Fifth Arab Report for cultural development, 2012). Perhaps this is because of the suffering of the Arab world in general and Egypt in particular regarding the issue of the migration of Arab brains abroad, which represents a real bleeding in the Arab mind. The figures show that $54 \%$ of the Arab students who study abroad do not return to their countries, and that Egypt alone lost in recent years about $60 \%$ of its scientists and researchers, due to their immigration to the United States of America (The Third Arab Report of cultural development, 2010).

Academic Rankings of universities have quickly established themselves among governments and institutions as good instruments for assessing the university performance. In this realm, this study explores whether the Egyptian universities can manage intellectual capital effectively. Benchmarking is used as a multifaceted method for assessing performance by identifying strategic and operational gaps, and searching for best practices that can be applied to bridge those gaps based on criteria for best comparative performance.

Table (1).The Times values for Arab universities and the top five global universities for the year 2018

\begin{tabular}{|l|l|l|l|l|l|l|}
\hline $\begin{array}{l}\text { World } \\
\text { Ranking }\end{array}$ & University & Education & $\begin{array}{l}\text { Scientific } \\
\text { Research }\end{array}$ & $\begin{array}{l}\text { industry } \\
\text { Return }\end{array}$ & Citations & $\begin{array}{c}\text { International } \\
\text { reputation }\end{array}$ \\
\hline
\end{tabular}




\begin{tabular}{|c|c|c|c|c|c|c|}
\hline 1 & Oxford & 91.8 & 99.5 & 99.1 & 67.0 & 96.3 \\
\hline 2 & Cambridge & 92.1 & $\begin{array}{l}98.8 \\
\end{array}$ & 97.1 & 52.9 & 94.3 \\
\hline 3 & Stanford & 93.6 & 96.8 & 99.9 & 64.6 & 79.3 \\
\hline 4 & $\begin{array}{l}\text { Massachusetts } \\
\text { Institute of } \\
\text { Technology }\end{array}$ & 91.9 & 92.7 & 99.9 & 87.6 & 89.0 \\
\hline 5 & $\begin{array}{c}\text { California } \\
\text { Institute of } \\
\text { Technology }\end{array}$ & 94.5 & 97.2 & 99.2 & 62.3 & 88.2 \\
\hline $201-250$ & $\begin{array}{c}\text { King } \\
\text { Abdulaziz }\end{array}$ & 27.8 & 16.3 & 99.0 & 77.2 & 92.9 \\
\hline $301-350$ & $\begin{array}{l}\text { King Faisal } \\
\text { University }\end{array}$ & 19.3 & 23.0 & 78.1 & 53.6 & 98.7 \\
\hline $351-400$ & $\begin{array}{c}\text { Jordan } \\
\text { University of } \\
\text { Science and } \\
\text { Technology }\end{array}$ & 15.2 & 7.8 & 98.3 & 36.9 & 63.6 \\
\hline $401-500$ & $\begin{array}{c}\text { Qatar } \\
\text { University }\end{array}$ & 18.4 & 24.1 & 62.5 & 53.1 & 99.8 \\
\hline 301-350 & $\begin{array}{c}\text { Khalifa } \\
\text { University }\end{array}$ & 25.3 & 29.1 & 65.3 & 100 & 96.4 \\
\hline $351-400$ & $\begin{array}{c}\text { United Arab } \\
\text { Emirates } \\
\text { University }\end{array}$ & 23.2 & 18.9 & 69.5 & 47.4 & 94.3 \\
\hline $601-800$ & $\begin{array}{c}\text { Banha } \\
\text { University }\end{array}$ & 14.7 & 7.7 & 52.1 & 35.3 & 39.9 \\
\hline
\end{tabular}

Source: http://www.timeshighereducation.com

It is clear from the previous Table(1), that six Arab universities are ranked for the first time among the top (500) universities in the Times ranking of international universities for the year 2018 AD, including two Saudi universities, namely (King Abdulaziz University, and AlFaisal University), in addition to two universities from the Emirates, namely the University of Khalifa University and the University of the united Emirates, while Qatar is represented by one university, and Jordan is represented only by one university, while no Egyptian university appeared among the best (500) universities in the world, and Benha University occupies the first rank for the year $2018 \mathrm{AD}$. As shown in the previous table, the value of international reputation of Qatar University is higher than that of Stanford University, the US ranked third globally in the Times for 2018, and also the Massachusetts Institute of Technology and the California Institute of Technology, which ranked fourth and fifth globally for 2018 , as well as the clear distinction of King Faisal University and the University of King Abdulaziz, Khalifa University, and the United Arab Emirates University are among the best universities in the world in the international reputation index, which is reflected in the ratio of foreign students to locals, as well as the ratio of foreign professors to locals, in addition to the published research rate for A university in which participants from other countries have contributed. Thus, this indicates that these universities are superior to others in the ability to attract competencies from human capital and invest them optimally. The international reputation criteria includes an index of the proportion of foreign students, which represents (43\%) for Qatar University in 2018, and that indicator has reached $(40 \%)$ for Al-Faisal University in Saudi Arabia, regarding this high percentage when compared to the proportion of foreign students at Oxford University , Which reached $(40 \%)$ in the same year, and the percentage of foreign students at Cambridge

University, which amounted to (37\%), and the proportion of foreign students also at Stanford University, which amounted to $(23 \%)$ in the same year. The number of times that a published work by the university is referred to at the global level indicates the continued keenness of universities on international scientific publishing in magazines classified internationally.

The Egyptian universities ranking can be shown among the best (1000) universities in the world according to the British Times ranking for the year 2018 AD, according to the evaluation indicators obtained by each university as shown in the following table(2).

Table (2).Ranking of Egyptian universities according to the British Times indicators of international universities for the year $2018 \mathrm{AD}$

\begin{tabular}{|c|c|c|c|c|c|c|}
\hline $\begin{array}{l}\text { World } \\
\text { Ranking }\end{array}$ & University & Education & $\begin{array}{l}\text { Scientific } \\
\text { Research }\end{array}$ & $\begin{array}{c}\text { industry } \\
\text { Return }\end{array}$ & Citations & $\begin{array}{l}\text { International } \\
\text { reputation }\end{array}$ \\
\hline $601-800$ & Banha & $\begin{array}{ll}14.7 \\
\end{array}$ & 7.7 & 52.1 & 35.3 & 39.9 \\
\hline $601-800$ & Beni Suef & $\overline{15.0}$ & 7,1 & 64,3 & 34 & 43,3 \\
\hline $601-800$ & $\begin{array}{l}\text { Kafr El- } \\
\text { Sheikh }\end{array}$ & 11,2 & 7,4 & 63,8 & 38,2 & 46,3 \\
\hline $601-800$ & Mansoura & 16,8 & 8,9 & 59,2 & 40,5 & 43,4 \\
\hline $601-800$ & Suez Canal & 17.6 & 7.6 & 69.0 & 35.3 & 45.5 \\
\hline $\begin{array}{l}801- \\
1000\end{array}$ & Alexandria & 15.3 & 10,3 & 27,4 & 40,7 & 44,4 \\
\hline $\begin{array}{l}801- \\
1000\end{array}$ & Cairo & 19.3 & 12,1 & 35,0 & 35,2 & 34,8 \\
\hline $\begin{array}{l}801- \\
1000\end{array}$ & Fayoum & 13,6 & 7,2 & 30,5 & 34,0 & 39,4 \\
\hline $\begin{array}{l}801- \\
1000\end{array}$ & Sohag & 18,5 & 7,3 & 8,9 & 34,3 & 43,6 \\
\hline+1001 & Tanta & 32.8 & 7,2 & 26,1 & 34,1 & 40,4 \\
\hline+1001 & Ain Shams & 17.6 & 8.7 & 17.4 & 35.5 & 36.1 \\
\hline+1001 & Assiut & 14.1 & 7,2 & 19,9 & 34,0 & \\
\hline+1001 & Helwan & 15.7 & 7.5 & $\begin{array}{ll}17.7 \\
\end{array}$ & 34.3 & 40.2 \\
\hline+1001 & Menoufia & 13,4 & 7,4 & 15,5 & 36,6 & 36 \\
\hline+1001 & Minia & 14.3 & 7 & 13,2 & 34,1 & 44,6 \\
\hline+1001 & $\begin{array}{l}\text { University } \\
\text { s. El Wadi }\end{array}$ & $\begin{array}{ll}10,7 \\
\end{array}$ & 7,1 & 23,2 & 34,1 & 44,8 \\
\hline+1001 & $\begin{array}{l}\text { Zagazig } \\
\end{array}$ & 12,9 & 7,2 & 18,7 & 34,0 & 38,4 \\
\hline
\end{tabular}

Source: http://www.timeshighereducation.com

It is clear from the previous Table(2) the extent of the variation in the ratios obtained by the Egyptian universities in each of the ranking indicators, the University of Benha ranked first among the Egyptian universities in the Times ranking for the year $2018 \mathrm{AD}$, and this is the first time that the University of Benha appears in the ranking of Times, followed by the rate of achieving ranking standards such as each of Beni Suef University, Kafr El-Sheikh, Mansoura, and the Suez Canal. This indicates the continued keenness of those universities to apply quality standards in order to achieve the Times ranking indicators.

It is clear that Cairo University is higher than other Egyptian universities in the criteria of scientific research, as it reached (12.1) in that criterion, which is reflected by both the university's research reputation. Also, and the amount of research revenue versus university faculty members, In addition to the research productivity of the 
university. Minya University achieved the lowest value in that indicator compared to other universities.

This is in addition to the Suez Canal University's superiority from other Egyptian universities in the standard of citations, by a rate of (69.0) in that criteria, which reflects the number of times that a published work by is indicated on the international level, which indicates the university's keenness On international scientific publishing in international journals with a high impact compared to other Egyptian universities, it is also clear that the University of Alexandria is higher than other universities in the criteria of return from industry, as the ratio reached (40.7) in that criterion, which reflects the amount of university research income from industry Compared to the numbers of faculty members.This indicates The university's ability to transfer knowledge compared to other Egyptian universities. It is clear that Kafr el-Sheikh University is higher than other universities in the criteria of international reputation, where the percentage achieved (46.3) compared to other Egyptian universities.

Over decades, Egypt was able to form a scientific base in various fields, and the number of researchers has increased from $(110,772)$ in 2013 to $(124,976)$ researchers in 2014, namely 13\%, and the number of Workers involved in research and development with a Full - Time Equivalent has increased from (47652) for 2013 to $(61058,55)$ researchers for 2014 , namely $28 \%$ (), and in 2016 the total number of researchers in Egypt reached $(132,085)$ researchers, the total number of researchers has increased $40 \%$ over the last five years. The public education sector includes the largest number of researchers, namely $77.8 \%$ of the total number of researchers (Academy of scientific research,2016)

Table (3) .of Rank of universities by publications / Researchers

\begin{tabular}{|l|l|l|l|l|}
\hline Rank & University & Publications & Researchers & $\begin{array}{l}\text { Publication/ } \\
\text { Researcher }\end{array}$ \\
\hline 1 & Suez & 106 & 427 & 0.2482 \\
\hline 2 & Kafr El-shaykh & 218 & 918 & 0.2375 \\
\hline 3 & Mansoura & 1174 & 5163 & 0.2274 \\
\hline 4 & Cairo & 2759 & 12907 & 0.2138 \\
\hline 5 & Assiut & 818 & 3828 & 0.2137 \\
\hline 6 & Alexandria & 1295 & 6675 & 0.194 \\
\hline 7 & Beni Suef & 343 & 1785 & 0.1922 \\
\hline 8 & Suez Canal & 544 & 2950 & 0.1844 \\
\hline 9 & South Valley & 229 & 1253 & 0.1828 \\
\hline 10 & Sohag & 286 & 1636 & 0.1748 \\
\hline 11 & Tanta & 635 & 3846 & 0.1651 \\
\hline 12 & Ain Shams & 1672 & 10200 & 0.1639 \\
\hline 13 & Damanhur & 144 & 928 & 0.1552 \\
\hline 14 & Port Said & 148 & 958 & 0.1545 \\
\hline 15 & Minufiya & 486 & 3307 & 0.147 \\
\hline 16 & Zagazig & 843 & 5880 & 0.1434 \\
\hline 17 & Minia & 412 & 2984 & 0.1381 \\
\hline 18 & Al-Fayoum & 233 & 1764 & 0.1321 \\
\hline 19 & Sadat City & 73 & 646 & 0.113 \\
\hline 20 & Banha & 388 & 3486 & 0.1113 \\
\hline 21 & Helwan & 452 & 4216 & 0.1072 \\
\hline 22 & Damietta & 75 & 774 & 0.0969 \\
\hline 23 & Aswan & 30 & 569 & 0.0527 \\
\hline 24 & Al-Azhar & 664 & 13178 & 0.0504 \\
\hline & & & & \\
\hline
\end{tabular}

Source: Adapted from Academy of scientific research,2014,p.103

The previous Table(3) shows that the University of Suez occupies the first rank in terms of the ratio of international publications to the number of researchers at the university, achieving a ratio of (0.2482), followed by the University of Kafr El-Sheikh with a percentage of (0.2375), followed by Mansoura University with a percentage of (0.22274). Cairo University achieves the fourth rank with a percentage of $(0,238)$, after it was in 2013 in the first rank in terms of the number of international publications to the number of researchers at the university. The University of Suez came for 2013 achieved the fourteenth rank with a percentage of (0.14).Also, the University of Kafr ElSheikh achieved the eleventh rank with percentage (0.16) during the same year.(Academy of scientific research,2016)

The ranking of Egyptian universities for the indicator of scientific citations has also decrease. This indicator also reflects the number of times that a research work published by the university is indicated at the international level. The Egyptian universities achieved a low ranking in the scientific research criteria. Banha University - ranked first locally in $2018 \mathrm{AD}$ - a ratio of (52.1) in the citations index, and a ratio of (7.7) in the scientific research index, and these ratios are low compared to what the University of Oxford ranked first in the world, where it got the ratios (99.5), (99.1) in both indicators, according to the Times classification of international universities for the year 2018 AD. According to the Egyptian Observatory for Science and Technology, the following table shows the ranking of the top ten more productive research institutions locally in terms of the number of scientific publications and citations in the period between 2010 and 2014.

Table (4). Rank of top 10 productive Institutions in Egypt in publication

\begin{tabular}{|l|l|l|l|}
\hline Rank & University & $\begin{array}{l}\text { Publications } \\
2010-2014\end{array}$ & $\begin{array}{l}\text { Citations } \\
2010-2014\end{array}$ \\
\hline 1 & Cairo University & 11832 & 50078 \\
\hline 2 & Ain Shams University & 7037 & 29391 \\
\hline 3 & National Research Center, Cairo & 6202 & 26880 \\
\hline 4 & Alexandria University & 5047 & 20020 \\
\hline 5 & Mansoura University & 4912 & 21209 \\
\hline 6 & Assiut University & 3305 & 14312 \\
\hline 7 & Zagazig University & 3183 & 11860 \\
\hline 8 & Al-Azhar University & 3001 & 11750 \\
\hline 9 & Suez Canal University & 2437 & 14763 \\
\hline 10 & Tanta University & 2417 & 9380 \\
\hline
\end{tabular}

Source: Adapted from Academy of scientific research, 2014, p.104

The previous Table(4) shows The breakdown of the total patents granted in the Egyptian Patent Office by country of origin shows that, the largest percentage of patents granted were for the European and American countries 
(45.4 and $32.9 \%$ respectively) (non-resident). On the other hand, patents granted to Egyptians were only $18.5 \%$ in 2013. (Academic of scientific research, 2016)

Also, (Swot) Analysis of the competence of Egyptian universities to manage its intellectual capital concluded that Egyptian universities suffer from several weaknesses which indicate that Egyptian universities are still unable to invest their intellectual capital. Mainly, The system of scientific research in Egyptian universities is still unable to manage the intellectual assets, due to weaknesses in human resources, structural resources, and relational resources, that lead to a gap between the optimized performance and reality, therefore this gap is represented in Egyptian universities inability to achieve competitiveness .Gap analysis is followed by the identification of strategic alternatives and the selection of the most appropriate alternative to cross this gap. The strategic alternative is the outcome of a sequential and interrelated process, namely, it is determined after identifying strengths and weaknesses, opportunities and challenges which are the result of environmental analysis, and then determining the best alternative according to strategic analysis

\section{Swot matrix}

Swot matrix represents the extent to which the ability of Egyptian universities to manage their intellectual capital, according to the data resulting from the environmental analysis, as follows:

\section{Strengths}

According to content analysis of statistical reports and literature, we conclude that:

1) The lack of strengths that characterize Egyptian universities in their ability to manage Intellectual capital

2) Egyptian universities have a lot of strengths , as follows:

3) The largest number of researchers is in the higher education sector, approximately $77.8 \%$ of the total number of researchers.

4) The presence of most faculty members in the governmental universities, $87 \%$, so that their effort can be invested and channeled optimally.

5) The presence of 42 Egyptian scientists in the position of president of a university abroad according to data of the General Union of Egyptians Abroad - that can enrich the scientific research system in Egypt by exchanging experiences with countries ranked internationally.

6) Egyptian universities have human capital of researchers, as most of those enrolled in postgraduate studies at the governmental universities.
7) There are more than $26,000 \mathrm{PhD}$ students in the applied sciences sector, followed by humanities and social sciences.

8) Egyptian universities have institutional structures that can be developed to support R\&D system especially innovation offices and technology incubators.

9) Egyptian universities have academic websites, which can be developed to improve their international reputation as a mirror that reflects intellectual capital stock in each university.

10) The medical sciences sector ranks first in the distribution of delegates outside Egypt, and this can enrich the R\&D system.

\section{Weaknesses}

According to content analysis of statistical reports and literature, we conclude that:

1) The multiplicity of weaknesses that Egyptian universities suffer from, regarding the competence of investing intellectual capital

2) The competence of Egyptian universities to manage intellectual capital suffers from many weaknesses, as follows:

3) The ambiguity of the philosophy directed at university education. Egyptian universities are still traditional stereotypes based on narrow specializations.

4) Absence of a clear and comprehensive system with laws and legislations that stimulate innovation.

5) Universities production is restricted to scientific publishing for the purpose of promotion, which leads to the reluctance of those who seek to make efforts to obtain contracts with industry.

6) The limitations of Egyptian universities marketing policies as homes of expertise to expand participation in development and technological projects.

7) No link between the strategies of universities with the broader strategy for scientific research and the country's development strategy.

8) The absence of research policies focused on the applied side of the link between scientific research and industry and production institutions.

9) The absence of a clear policy for postgraduate studies and research within the same university, and poor coordination between colleges and the scientific trends that exist at the university level.

10) Few priorities for research projects within universities and no implementation in development plans.

\section{Opportunities}

1) The lack of opportunities that characterize Egyptian universities in their ability to manage Intellectual capital

2) According to (The ministry of planning and administrative reform,2017) we conclude that 
3) During year (2016/2017), the tourism sector in Egypt achieved a growth rate of $110 \%$.

4) Establishing the Egyptian Space Agency with the aim of creating, transferring, settling and developing space technology science.

5) The launch of the Egyptian Knowledge Bank, which represents a cultural heritage that includes $(15,000)$ periodicals and $(350,000)$ books, which saves a lot of time, effort and money.

6) The large number of institutional structures in the fields of research and development outside universities can enrich the research activity and link it with development plans.

7) The diversification of economic activities within the framework of the national economy, and the need of many of research efforts to achieve competitiveness.

8) Launching the Academy of Scientific Research and Technology of the National Program for Technological Alliances (EG-KTAs) to link scientific research with industry in an effective way, with the aim of producing or developing a local product and supporting the national industry.

9) Allocating at least $1 \%$ of national income to support scientific research.

10) International parties welcome the participation of the Egyptian entities in highly competitive international programs to support infrastructure and support joint applied research.

\section{Challenges}

The multiplicity of challenges faced by Egyptian universities, regarding the competence of investing intellectual capital we conclude that:

1) Low economic growth rates and a small size of the gross domestic product, as it reached (4.4\%) in 2017.

2) The Egyptian economy achieved negative growth rates in the extracting and oil refining sectors during 2016-2017

3) the poor distribution of income and wealth in a way that fundamentally affects economic growth and the allocation of resources to acquire knowledge, in a way that affects the financial allocations of Egyptian universities.

4) The value of the public debt more than two and a half times within five years, from (1.24) trillion pounds in June 2012 to about (3.16) trillion pounds in June 2017.

5) Increasing the deficit in the trade balance, due to the decrease in the performance of the main commodity production sectors, and weak performance of the industrial and agricultural sector.

6) High inflation rate, because of the liberalization of the exchange rate of the Egyptian pound against the US dollar 2016, which negatively affected the scientific research system.

7) Lack of specific mechanisms for coordination between research and development institutions inside and outside universities.

8) The decrease in the percentage of Egyptians who belong to political parties, which reflects the inefficiency of the Egyptian youth role.

9) Population growth led to pressure on educational institutions, so the increased demand for education was reflected in the educational policies in Egypt.

10) The tendency of the country to adopt a general policy to rationalize expenditures in the field of higher education, which has affected the efficiency of outputs .

\section{Discussion}

With regard to Benchmarking and Gap analysis, it can be concluded that:

- The ability of Egyptian universities (managing intellectual capital) has little strength.

- Egyptian universities suffer from many weaknesses that limit their competence to manage intellectual capital.

- -Egyptian universities face various challenges that limit their ability to achieve effective management of intellectual capital.

- Swot matrix determines the most appropriate strategic Alternative to improve the ability of Egyptian universities to manage intellectual capital. Weaknesses

- Challenges strategy is defensive strategy, that help Egyptian universities to overcome Weaknesses, transforming them in to strengths .

After the success of the Weaknesses - Challenges strategy in accomplishing its mission by turning The weaknesses in to strengths, facing challenges ,converting them in to opportunities. Then the situation becomes ready to adopt another strategic alternative, which is an offensive strategy, helping Egyptian universities expand their ability to manage Intellectual capital.

\section{Recommendation}

- The necessity of developing a strategic plan to increase research productivity and scientific international publishing

- Employing creative competencies in universities in influential locations that provide an opportunity to take advantage of new ideas and to achieve the university's competitiveness.

- Developing the academic and administrative skills of faculty members, and encourage publication in international periodicals with a high impact factor . 
- Increasing the participation of the faculty members in the training courses in each university for training on writing scientific research in the English language.

- Increasing the incentives offered by the university to the faculty members to encourage research innovation and international scientific publishing.

- Encouraging the faculty members for electronic training via distance, by providing communication networks among faculty members inside the university and researchers in other research institutions.

- Investing the growing number of doctoral students and enhancing the research capabilities of productive institutions, by holding cooperation protocols that provide these institutions with researchers in their field of expertise, in order to enrich the relationship between research and practical application.

- Encouraging researchers to compete for international awards such as the Nobel Prize and the Fields Mathematics Awards.

\section{Acknowledgements}

Primarily, I would thank allah. Then I would like to express my sincere gratitude to my advisor Prof $\backslash$ Samir Abdelwahab El-Khweet for the continuous support of my Ph.D study and this study, for his patience, motivation, enthusiasm, and immense knowledge. His constant guidance and advice helped me all the time .

\section{References}

[1] Academy of Scientific Research Technology(2014), Egyptian Science and Technology Indicators :Egyptian science, Technology and innovation observatory (ESTIO), Egypt, p.70

[2] Adenan.H et al (2014), The Human Resource Strategies that motivate Knowledge sharing Behavior: Case Study from selected Malaysian Private Universities, in: Rooney. $\mathrm{J} \&$ Murthy. $\mathrm{V}$, proceelings of the $\mathbf{1 1}^{\text {th }}$ International Conference on Intellectual Capital, Knowledge Management and Organizational Learning ICICKM 2014, the university of Sydney Business school, Australia, 6-7 November, P.452-453

[3] Bontis . N.(2002), World Congress on Intellectual Capital Readings: Routledge, U.S.A, pp.163- 164.

[4] Caddy. I (2015), Intellectual Capital and Quality Management: Strange bedfellows or New Insights?, on Line Article, Available at www. aair. Org

[5] Chen .J et al (2004) ,Measuring Intellectual capital: a new model and empirical study, Journal of Intellectual capital, Vol.5, No.1, Emerald, P. 201-206.

[6] Cricelli. L et al (2018), Intellectual Capital and university performance in Emerging Countries: Evidence Fom Colombian public Universities, Journal of Intellectual Capital, Vol.19, No.1, p.76.

[7] Jakson .P\& Wielen. J (2002), Teleworking: International Perspectives From Telecommuting to the Virtual organization: Routledge, London, p.171.
[8] Ling.Y (2012) ,Study on The influence of intellectual capital complementarity on global initiatives: Electronic Journal of Knowledge Management Volume 10 Issue 2 , Emerald ,p154

[9] Lu. W. (2012) , Intellectual Capital and university Performance in Taiwan: Economic Modeling Journal, Vol. 29, NO.4, Elsevier, p.1087.

[10] Marr. B(2004), Measuring and Benchmarking Intellectua Capital: Benchmarking: An International Journal, Vol .11, No.6, Emerald, P.563,p.564 .

[11] Observatory of European University (2006), Strategic Management of University Research activities, Methodological Guide, PRIME Network of Excellence funded at by the European commission, lungano November, P.17.

[12] Pourkian, $M$ et al (2014) ,Importance and Status of intellectual Capital In Knowledge Economy: Indian Journal of fundamental and Applied life Sciences ,Vol.4, Centre for Info Bio technology, NetherLands, p. 512

[13] Ramirez. Y \& Tejada. A (2016), The value of disclosing Intellectual Capital in Spanish universities: A new challenge of our days, Journal of Organizational change Management, Vol.29, No. 2, Emerlad Group publishing limited, p. 182.

[14] Ramirez. Y et al (2007), Intellectual Capital management in Spanish Universities: Journal of Intellectual Capital, Vol.8, No.4, Emerald Group Publishing limited, Spain,p. 732-748

[15] Secundo .G et al (2015), Intellectual Capital in Academic Entrepreneurship: Moving Beyond Measurement, In Garlatti .A8 Massaro .M: proceedings of the 16th European conference on knowledge Management, acpi, university of Udine, Italy, 3-4 September, P. 688-689.

[16] Secundo. G et al (2017), An Intellectual Capital framework to measure Universities Third mission activities: Technological forecasting \& Social change 123, El SEVIER, p. 232.

[17] Siboni. B et al (2013), Italian State university Contemporary Performance plans: an Intellectual Capital Focus? , Journal of Intellectual Capital, Vol.14, No.3, Italy, p. 418

[18] Stewart et al (2009) , Business Essential, Bloosbury Information: An imprint of Bloosbury Publishing P1c, London, p. 30.

[19] The Fifth Arab Report for Cultural Development (2012), Knowledge-based Arab Economy: Arab Thought Foundation for publishing, Beirut-Lebanon, pp.12- 15.

[20] The ministry of planning and administrative reform (2017), Report of monitoring Economic and Social performance during the fourth quarter for the year2015-2016, Egypt.

[21] The Third Arab Report for Cultural Development (2010), Scientific Research in the Arab World: Indicators of Backwardness and Attempts to Excellence, Arab Thought Foundation, Beirut-Lebanon, p. 40.

[22] Vătămănescu. E ,et al (2012), "Networking Intellectual Capital towards Competitiveness: An Insight into the European Higher Education Institutions" The Electronic Journal of Knowledge Management Volume 13 Issue 3 , p. 220 available online at www.ejkm.com 